\title{
Uma comunidade infraleve - João Barrento, Maria Filomena Molder e Raúl Antelo: leitores de Walter Benjamin
}

\author{
Manoel Ricardo de Lima ${ }^{1}$ \\ Programa de Pós-graduação em Memória Social, Universidade Federal do Estado do Rio de Janeiro, Rio de \\ Janeiro, RJ, Brasil
}

Resumo: O texto é uma pequena apresentação de leitura crítica e procedimento dos modos de uso e incorporação de certas questões dispostas e reposicionadas entre as ideias de arquifilologia, geografia imaterial e memórias inaparentes em três leitores de Walter Benjamin que modulam-lhe o pensamento numa seriação imprevista compondo assim uma comunidade infraleve: João Barrento, Maria Filomena Molder e Raúl Antelo.

Palavras-chave: Walter Benjamin; Infraleve; Memórias; Arquifilologia; Imaterialidade.

Title: An infralight community - João Barrento, Maria Filomena Molder and Raúl Antelo: readers of Walter Benjamin

Abstract: The text is a small presentation of critical reading and procedure of the ways of use and incorporation of certain disposed and repositioned questions between the ideas of arquifilologia, imaterial geography and memories unapparent in three readers of Walter Benjamin that modulate the thought to him in an unforeseen seriation composing thus an infraleve community: João Barrento, Maria Filomena Molder and Raúl Antelo.

Keywords: Walter Benjamin; Infraleve; Memory; Arquifilology; Imateriality.

La publicaré proximamente, pues ya han dicho admirados los críticos de manuscritos, "es novela que nunca antes se ha escrito". E ahora tampoco, pero falta poco.

Macedonio Fernández

No ano 2000 a crítica argentina Beatriz Sarlo reuniu num pequeno livro editado pelo Fondo de Cultura Económica alguns ensaios em torno do pensamento de Walter Benjamin: Siete ensayos sobre Walter Benjamin. Em 2013, o crítico e tradutor português do pensador alemão, João Barrento, publica no Brasil, editado pela Universidade Federal de Santa Catarina, EdUSFC, um livro que reúne também, numa coincidência, sete ensaios

\footnotetext{
${ }^{1}$ Doutor em Teoria Literária e Literatura Brasileira pela Universidade Federal de Santa Catarina. Professor da Universidade Federal do Estado do Rio de Janeiro, UNIRIO. Orcid: https://orcid.org/0000-0001-9243-6597

E-mail: manoelrl@uol.com.br
} 
engendrados para algumas questões fundamentais do autor de Das Passagen-Werk: Limiares sobre Walter Benjamin. A partir do primeiro impasse sugerido por um ensaio de Sarlo daquele livro, Olvidar a Benjamin, de que a academia tende a generalizar tudo o que toca e a promover processos de decomposição que foram introduzidos pelas ditaduras militares no continente latino americano e, em particular, caso que ela indica, na Argentina, inferindo assim uma normalização do saber seguindo as regras fixas da academia, termina por apontar para uma "moda Benjamin" que é elaborada sempre parodicamente. (2000, p. 78) Ela diz, num exemplo, que

La lectura de Benjamin (y, junto con él como si se tratara más o menos de lo mismo, de Schorske, Bermanm, Sennett, De Certeau, Augé, Baudrillard, entre muchos) há producido una especie de erosión teórica que carcome lá originalidade benjaminiana hasta los limites de la completa banalización. Decir que estamos frente a un caso de empobrecimento semântico es poco. Benjamin está ensopado en un jarabe puramente léxico: se lo cita como se la cita asegurara, como a veces la aseguraba a Benjamin después de mucho trabajo compositivo e histórico, la produción de un sentido nuevo sobre escenarios diferentes.

$[\ldots]$

Benjamin no estudió ciudades porque fuera un tema a la moda. Buscó sentidos y, naturalmente, encontró a las ciudades como escenario. No viajó a Moscú para escribir el diário de la visita a una gran capital. Persiguió hasta Moscú a un amor doble: fue allí por una mujer y una idea de revolución. Y, naturalmente, no encontro del todo a ninguna de las dos. (SARLO, 2000, p. 79-80)

De outro modo, anos depois, João Barrento, estica o procedimento de Benjamin e convoca a uma afirmativa do sentido de decomposição propondo ler o que vem entre enigmático e luminoso, móvel e dessemelhante, oblíquo e prismático, numa ideia de limiar que, quase de maneira intransmissível, só pode ser lida rigorosamente "do ponto de vista do presente". (2013, p. 13) Assim, aposta numa série alargada e abrangente sugerindo que Benjamin é o arquiteto de "uma sabotagem construtiva", um "revolucionário do silêncio", um "profeta para a posteridade" ou "um visionário no mundo burguês" (2013, p. 63), o que Ihe retiraria dessa generalização de uma "moda Benjamin" lançando-o a uma exigência, ou a uma emergência, que seria a de lê-lo sob a oscilação severa e contaminante daquilo que ele jamais sequer escrevera. Como a ideia de que o historiador, como indica numa das notas para suas Teses, precisa saber "ler o que não foi escrito". João Barrento acresce que Benjamin é

um leitor de indícios, operando um "desvio» em relação às leituras dominantes (de factos ou de quimeras) que, por pequeno que seja, implica, naturalmente, riscos. A permanência no limiar contém o perigo da indecisão (nada que Benjamin não conhecesse bem), a "topografia dos limiares" (Menninghaus), físicos e simbólicos, integra os extremos da protecção e do medo do desconhecido [...]. Mas o "método" seguido 
implica e integra esses riscos, e é largamente compensado pela "salvação" que propicia do que há de mais essencial nos objectos - quase sempre textos - de que se ocupa: aquilo a que chama o seu "conteúdo de verdade".

Se tivesse de resumir numa frase o método de Benjamin, diria que ele pretende descobrir o mais distante pela observação incansável e implacável do mais próximo. E isto exige um "desvio", seguindo por vezes os mais imprevisíveis caminhos que levam à percepção do "modo de ser simples das coisas". (BARRENTO, 2013, p. 117)

Daí, que ainda confirme uma decisão de Benjamin acerca de seu método:

(em que o objecto/a obra não é acidente histórico, mas substância de um passado para a iluminação de um presente) não tem lugar o Eu: Benjamin decidiu um dia, ainda nos anos vinte, não usar a palavra "eu" nos seus escritos. Mas que significa dizer EU, ou silenciar o EU? [..]. Quando Walter Benjamin pergunta "Sou eu aquele que se chama W. B., ou chamo-me simplesmente W. B.?", e se decide pela primeira hipótese, está a decidir-se pelo Ser, e não pelo Nome, a introduzir entre si e si, num limiar da consciência, uma distância preenchida por uma história que é uma acumulação de experiência (Erfahrung), diferente da mera vivência pessoal (Erlebnis), e que lhe permite chegar a um terceiro, mais autêntico, um Selbst: o si-próprio que é nome próprio - este é, para o indivíduo W. B., o seu "conteúdo de verdade" (Maria Filomena Molder desenvolveu já este tema num dos seus mais brilhantes ensaios, em que se interroga sobre a questão do indivíduo em Benjamin). (BARRENTO, 2013, p. 119-120)

Nesse contraponto inicial, tem-se, ao mesmo tempo, um enlace e um desenlace, do que ainda podem ser algumas leituras de Walter Benjamin agora, nesse presente, ainda mais quando se trata de um vórtice produzido por um pensamento em espiral: quando as pontas dessa linha, ou desse procedimento, tendem a um começo que vem do infinito e a um termo que também tende ao infinito. O apontamento de João Barrento se dirige ao texto de Benjamin publicado em 1931, Sobre a faculdade mimética, quando este remete a uma perspectiva aberta que nos parece seminal ao seu procedimento: o de que é o ser humano que tem a capacidade máxima de produzir semelhanças, um dom para ver as semelhanças imateriais entre os sentidos filogenético e ontogenético. Um bom exemplo para esse empenho de uma leitura do imaterial, como a ruína, são os jogos infantis. Benjamin sempre manteve um verdadeiro fascínio pela criança e seus modos de imitação e expansão, daí advêm também suas preocupações com o ensino e a educação com uma formação que contraria as práticas burguesas e pode construir uma nova memória. Tanto que entre 1929 e 1932, Benjamin manteve um programa de rádio para crianças, A hora das crianças, antes já estendera esses planos com os textos reunidos em Rua de mão única (1928) e, depois, seus ensaios reunidos entre a criança, o brinquedo e a educação, sempre propondo práticas liberadoras e desburocratizadas contra a estratégia de mercantilização do conhecimento preocupada em formar apenas especialistas. Na criança, para ele, há um modo de estar no 
mundo, lançar-se ao mundo, entre o olhar e todo o corpo, ou olhar com todo o corpo, atrairse pelo mundo, que é inteiramente mágico. Daí que ele proponha ler o presente não apenas através da materialidade da linguagem e sua obscuridade canônica, mas também do que chama de "semelhanças não-sensíveis"; diz ele que essas semelhanças é que podem traçar uma ligação entre a fala e o que ela tenta dizer, entre o escrito e que ele pode significar e, ainda, entre o falado e o escrito. E afirma, como articulação imaginativa desse procedimento:

\begin{abstract}
"Ler o que nunca foi escrito". Esta forma de leitura é a mais antiga: a leitura antes de toda a linguagem, a partir das entranhas, dos astros ou da dança. Mais tarde apareceram instrumentos intermediários de novas formas de leitura, runas e hieróglifos. Tudo indica que foram estes os estádios que permitiram a entrada na escrita e na linguagem daquele tom mimético que em tempos fora o fundamento das práticas ocultas. Assim sendo, a linguagem seria o grau mais elevado do comportamento mimético e o mais completo arquivo de semelhanças não-sensíveis: um medium para o qual migraram definitivamente as antigas forças da ação e da ideia miméticas, até ao ponto de liquidarem as da magia. (BENJAMIN, 2015, p. 59)
\end{abstract}

Entre o que toma como "velocidade da escrita" e "leitura potente", a sugestão radical de "ler o que nunca foi escrito", num medium, pode ser aberta e reaberta na constituição de uma comunidade de leitores que tenta lê-lo na sua possibilidade do impossível, mínima e máxima ao mesmo tempo, e que pode possibilitar o gesto da "passagem do reino lógico dos conceitos para o reino mágico das palavras". (BENJAMIN, 2016, p. 301) Ou seja, a possibilidade de imaginar outra vez - através de um trabalho de leitura que se dá no corpo e com o corpo diante de um rigoroso modo de proceder, o de Benjamin, que preza pela inaparência, pela imaterialidade, para desmontar o manual, a instrução, entre ausência e esquecimento - e de armar outras matizes contra o ordenamento histórico linear ainda tão forte nesses tempos de agora para a manutenção de certos imperativos de poder e controle.

Assim, seguindo uma disposição a um caráter destrutivo, como destruir a destruição (uma ideia que é retomada mais recentemente pelo pensador italiano Giorgio Agamben em alguns ensaios de seu livro Infância e história, ver bibliografia, quando Benjamin aparece também como alquimista) ${ }^{2}$, é que Benjamin reclama uma potência para um pensamento que faça rejuvenescer: arejar, romper, abrir caminhos ou, como indica no seu texto acerca de uma "ciência da literatura" (1931) que "nada renova tanto quanto o esquecimento". (BENJAMIN, 2015, p. 27) Algo como se estivéssemos numa tentativa de ler o presente o

\footnotetext{
${ }^{2}$ Agamben chega a dizer, por exemplo, que "o materialista histórico é o alquimista que mantém seu olhar fixo na pira em que, assim como teor causal e teor de verdade, estrutura e superestrutura voltam a identificar-se" e que "a tarefa da crítica é saber reconhecer na estupefata facticidade da obra, que está diante de nós como fragmento filológico, a unidade imediata e originária de teor coisal e teor de verdade, de estrutura e superestrutura, que nela se fixou". (2005, p. 148)
} 
tempo inteiro pautados por aquilo que vem da montagem de superfícies e perdendo as possibilidades de que a experiência ainda possa romper essa montagem lançando também sobre ela um jogo de interfícies. Este último conceito, que diz muito da ideia de Benjamin de que a história é uma sucessão de catástrofes, aparece numa série de ensaios de Raúl Antelo, o crítico cultural e professor "argentino-brasileño", como prefere ser lido, nesse limiar, quando se apropria e incorpora o pensamento de Walter Benjamin sugerindo assim uma modulação, e um esgotamento, para reagir engendrando o que chama de "uma máquina afilológica": a história numa imaterialidade da literatura e da arte e não a literatura e a arte em mais uma materialidade da história. Ou seja, numa arquifilologia: colocar em contato dados distantes, por sua vez, não-aparentados, para que se produza um choque entre eles e nunca uma história autoconsciente, mas sim um relato deslocado, fora de si, no qual a linguagem se esquece de si mesma, como uma espécie de memória inaparente que advém de séries imprevistas e heterogêneas. O que aparece, nesse método ou procedimento, é uma maneira de tocar o fragmento filológico como se fosse à maneira da irreverência ou indisciplina de um jovem, uma espécie de diferimento do desejo que implica recuperar não apenas o sagrado, mas também o impuro, para contrariar a pedagogia modernizadora. Desse modo, aponta, lendo Angel Rama, a partir de $O$ posicionamento religioso da nova juventude, um ensaio de Benjamin de 1914, que

solo la cultura juvenil tiene esa posibilidad de agitarse ante lo contradictorio. [...] "La juventud - decía Benjamin - confia em que se revele lo sagrado y lo condenable en el instante en que su voluntad común de elección se oriente hacia lo más elevado". [...] Sin embargo, a Rama le cuesta aceptar la indisciplina de los nuevos. No admite que lo joven o incluso lo infantil jueguen como reinvindicación pública contraria a la pedagogía modernizadora. Esos valores apuntan, en efecto, a la repetición, al crear ex novo, y esto lo había compreendido agudamente Benjamin cuando detecto la anfibologia de Spielen (jugar, pero tambíen, contar). Recordamos hace poco a Walter Benjamin cuando nos decía que el niño perfora la pared ilusória de la superfície de las imágenes y, carnavalizando su discurso, se convierte a sí mismo en un diretor de escena que no se deja censurar por el sentido consabido. (ANTELO, 2014, p. 75, 81 e 82)

Nesse mesmo empenho, Maria Filomena Molder, filósofa e crítica portuguesa, move ainda uma outra sugestão de leitura do pensamento e do procedimento de Walter Benjamin num jogo de múltiplos e sem centro apresentando-o, antes de mais nada, entre a química e a alquimia, como um outro daquele já conhecido exímio leitor de Charles Baudelaire: $\mathbf{0}$ químico e o alquimista - Benjamin, leitor de Baudelaire (2011). Ela diz, por exemplo, refazendo o gesto do texto Um anjo de natal (do livro Infância Berlinense, de Benjamin), que para o pensador alemão todo o princípio da filosofia e da crítica se anuncia num momento decisivo diante da presença daquilo que enquanto vem, feito um anjo, também se desvanece. E afirma que "em Benjamin todo o conceito há-de sofrer sempre da irradiação desta experiência" e que "a partir do momento em que se celebra uma experiência, 
tentando retê-la, mesmo que seja numa canção, ela desvanece-se." (MOLDER, 2011, p. 43) Depois, em vários de seus livros expande os sentidos de uso dessas operações críticas para sua inespecífica maneira de proceder, basta ver e ler, como exemplo, livros mais diretamente vinculados a Benjamin, como Semear na neve: estudos sobre Walter Benjamin, publicado em 1999, ou os que passeiam raspando, mas sempre de modo imanente, no procedimento do crítico em livros como $\mathbf{O}$ absoluto que pertence à terra, de 2005, em torno de Hermann Broch, ou em Depósitos de pó e folha de ouro, publicado no Brasil em 2016.

Do limiar figurado entre o químico e o alquimista, numa tentativa de conhecer as coisas tal como são no preciso momento em que não são ou de, num esforço, subtrair os mortos ao esquecimento, ela acena com três apontamentos: 1] a partir de Goethe até Baudelaire, a elaboração do método de seguir os estremecimentos da agulha magnética em busca do norte apontado no prefácio da Origem do drama barroco alemão: "método é desvio"; 2] perceber simultaneamente a origem e o declínio das coisas e ainda perguntar-se se estes são eternos, assim eis a imagem dialética, quando uma imagem do passado poderia ser recolhida e salva; 3] acerca da ideia das pequenas imagens rápidas que coincidem com o agora das coisas, que é a imagem mais íntima do passado, para, ao mesmo tempo, produzir uma exigência: vencer a ilusão de que o passado nos pertence e está à nossa mercê. Seguindo esse mover da leitura, diante do Passagens, remonta a apocatástase, numa força (nunca numa forma) figurativa, descontínua e monadológica, e afirma:

para Benjamin não há épocas de decadência, não há cidades feias, não há línguas inferiores a outras, ou, melhor, a desagregação é uma espécie de "miragem que prefigura a grande síntese", obedecendo às exigências de um antigo método teológico, a apocatástase, a redenção exaustiva, sem resto. [...] Este método obedece ao princípio de que não há ninguém que mereça ser redimido, tudo merece ser salvo. [...]

Que as imagens do passado cheguem à sua legibilidade numa certa época é um sinal seguro de que o agora se tornou um ponto crítico, explosivo, perigoso, da história, momento em que o conhecimento de uma época se revela numa constelação dessa época com aquela daquele que a conhece, isto é, uma figura de um vínculo magnético, a que Benjamin chama "dialéctica suspensa", o movimento rememorativo contraído num esboço, numa imagem que interrompe e salva qualquer cronologia, qualquer falsa continuidade. (MOLDER, 2011, p. 116-117)

Dessa maneira, num começar, este disparador sempre político, entre esses três leitores de Walter Benjamin - os portugueses João Barrento e Maria Filomena Molder e o argentino-brasileño Raúl Antelo -, e uma virtualização de leitura, de leitor / leitores, a serem relidos como se compusessem uma comunidade quase imprevista. Importante salientar que nessa comunidade há um arremesso a outras possibilidades de articulação que são, também, o que se pode pensar como "um resíduo significante" e "uma projeção de sombra nos crivos" (ANTELO, 2010, p. 23): uma reexposição ou uma disposição ao que seria apenas 
um "regard" (um olhar) até uma dispersão pasmada entre um "retard" (um atraso) e o "hasard" (o acaso). Daí que o conceito de infraleve, recuperado por Raúl Antelo do artista francês Marcel Duchamp, a partir do contato deste com a artista brasileira Maria Martins, tratado em seu livro Maria com Marcel - Duchamp nos trópicos (2010), passa a ser tão importante nessa perspectiva. $E$ isto a partir do gesto do leitor e da leitura que projetam a impressão do pensamento e do procedimento de Walter Benjamin virtualizados criticamente noutra língua, no caso, o português, e noutros contextos sócio-culturais, casos do Brasil, Portugal e, com alguma expansão, em algo da América Latina, por causa dos interesses diversos de Raúl Antelo.

Esse conceito de Duchamp, grosso modo, uma espécie de "economia da dispersão e do gasto, assim como uma separação da matéria" (ANTELO, 2010, p. 17), sobrelevando-se, num engendramento, em torno de Benjamin, arma, num ajuntamento e num confronto desses leitores e dessas leituras, um dissensus naquilo que se equilibra simultaneamente entre a importância das formas e as transformações e metamorfoses que as desfazem, procedimento que pode ser entendido como uma força ou, ampliando o jogo, umas forças; uma espécie de movimento perseverante, imparável e político que imagina um pôr-se à prova, logo pôr-se à vida com força, ao invés de pôr-se em forma. Pode-se estender o sentido até a ideia de uma restituição que tome a leitura crítica de um pensamento fundamental para a modernidade, como um todo mas nunca totalizante, numa escassez da forma para torná-la cada vez mais estrangeira a cada tempo e menos exata o tempo inteiro. O que sugere, se estamos numa substituição do olhar pelo atraso, que se possa ler também uma esferologia elíptica e espiralada do anacronismo na tarefa política que cada um desses leitores busca cumprir diante de Walter Benjamin. Isto pode ser, como indica o próprio Benjamin, desta vez o leitor de Bachofen (num texto sobre este último, de 1924), mover-se num pensamento propulsor, como uma força, e nunca como uma forma, contra as perspectivas do estado técnico e mecanizado daquele mundo que ainda se vincula indefinidamente ao mundo atual, que "as imagens são almas, quer sejam almas de coisas, quer sejam almas de seres humanos" (BENJAMIN, 2013, p. 118); ou seja, uma tentativa de ler nas imagens de um passado remoto os elementos diferidos que thes atribuem a emergência de interdição utópica no presente, uma utopia irremediável, que ainda pode ser um futuro fabuloso de força. E isto, no gesto singular da leitura, por exemplo, possibilita criar forças de existência numa aventura ao contrário daquilo que se estabelece fixamente, já frase feita a todos os lados, como formas de resistência, e que não infere mais nenhuma advertência ou alteração a nada porque tudo já lhe é idêntico. Assim, ler no leitor e não apenas no autor; ler na leitura, ler com a leitura para expandir, radicalmente, todo "atraso originário". (ANTELO, 2010, p. 19) 


\section{Referências e bibliografia consultada}

AGAMBEN, Giorgio. Infância e História. Trad. Henrique Burigo. Belo Horizonte, EdUFMG, 2005.

ANTELO, Raúl. Transgressão e Modernidade. Ponta Grossa: UEPG, 2001.

ANTELO, Raúl. Tempos de Babel: Anacronismo e destruição. São Paulo: Lumme Editor, 2007.

ANTELO, Raúl. Ausências. Florianópolis: Editora da Casa, 2009.

ANTELO, Raúl. Maria com Marcel: Duchamp nos Trópicos. Belo Horizonte: UFMG, 2010.

ANTELO, Raúl. Imágenes de América Latina. Sáenz Peña: Universidad Nacional de Tres de Febrero, 2014.

BARRENTO, João. Umbrais. O Pequeno Livro dos Prefácios. Lisboa, Cotovia, 2000.

BARRENTO, João. Ler o Que Não Foi Escrito. Conversa inacabada entre Walter Benjamin e Paul Celan. Lisboa, Cotovia, 2005.

BARRENTO, João. Limiares. Sobre Walter Benjamin. Florianópolis, Editora da UFSC, 2013.

BARRENTO, João. Geografia Imaterial. Três ensaios sobre a poesia (com fotografias de Vina Santos). Lisboa, Documenta, 2014.

BENJAMIN, Walter. Origem do drama barroco alemão. Trad. Sérgio Paulo Rouanet. São Paulo, Brasiliense, 1984.

BENJAMIN, Walter. Charles Baudelaire: um lírico no auge do capitalismo. Trad. José Carlos Martins Barbosa e Hemerson Alves Baptista. 1. ed. São Paulo, Brasiliense, 1991. (Obras Escolhidas; v. 3)

BENJAMIN, Walter. Diário de Moscou. Trad. Hildergard Herbold. São Paulo: Cia. das Letras, 1989.

BENJAMIN, Walter. Imagens de Pensamento. Trad. João Barrento. Lisboa, Assírio e Alvim, 2004.

BENJAMIN, Walter. A modernidade. Trad. João Barrento. Lisboa, Assírio e Alvim, 2006.

BENJAMIN, Walter. Passagens. Org. Willi Bolle. Trad. Irene Aron e Cleonice Paes Barreto Mourão. Belo Horizonte, Editora UFMG; São Paulo, Imprensa Oficial, 2006.

BENJAMIN, Walter. O anjo da história. Trad. João Barrento. Lisboa, Assírio e Alvim, 2008.

BENJAMIN, Walter. Reflexões sobre a criança, o brinquedo e a educação. Trad. Marcus Vinícius Mazzari. São Paulo, Ed. 34, 2002.

BENJAMIN, Walter. Origem do drama trágico alemão. Trad. João Barrento. Belo Horizonte, Autêntica, 2011.

BENJAMIN, Walter. 0 capitalismo como religião. Trad. Michael Löwy. São Paulo, Boitempo, 2013.

BENJAMIN, Walter. Rua de mão única, Infância Berlinense: 1900. Trad. João Barrento. Belo Horizonte, Autêntica, 2013. 
BENJAMIN, Walter. A hora das crianças. Trad. Aldo Medeiros. Rio de Janeiro, Nau Editora, 2015.

BENJAMIN, Walter. Linguagem, tradução, literatura. Trad. João Barrento. Lisboa, Assírio e Alvim, 2015.

BENJAMIN, Walter. Ensaios sobre literatura. Trad. João Barrento. Lisboa, Assírio e Alvim, 2016.

BENJAMIN, Walter. História da literatura e ciência da literatura. Trad. Helano Jader / Posfácio. Manoel Ricardo de Lima. Rio de Janeiro, 7Letras, 2016.

D’ANGELO, Martha. Arte, educação e política em Walter Benjamin. São Paulo, Loyola, 2006.

DERRIDA, Jacques. Força de lei. Trad. Leyla Perrone-Moisés. São Paulo, Martins Fontes, 2007.

LÖWY, Michael. A estrela da manhã - surrealismo e marxismo. Rio de Janeiro, Civilização Brasileira, 2002.

MOLDER, Maria Filomena. A Filosofia e o Resto. Lisboa, Edições Colibri, 1996.

MOLDER, Maria Filomena. Semear na neve: estudos sobre Walter Benjamin. Lisboa, Relógio D'Água, 1999.

MOLDER, Maria Filomena. O químico e o alquimista: Benjamin, leitor de Baudelaire. Lisboa, Relógio D'água, 2011.

MOLDER, Maria Filomena. Dia alegre dias pensantes dias fatais. Lisboa, Relógio D'água, 2017.

SARLO, Beatriz. Siete ensayos sobre Walter Benjamin. Buenos Aires, FONDO DE CULTURA ECONOMICA, 2000.

Recebido em: 27/05/2019

Aceito em: 23/08/2019 